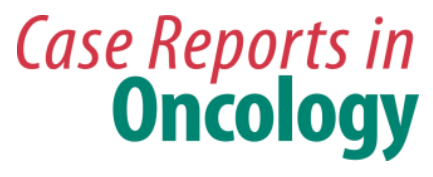

Case Rep Oncol 2017;10:851-856

\title{
Primary Hepatic Angiosarcoma: A Case Report with 10-Year Patient Medical Data
}

\author{
Masanori Ogawa $^{a} \quad$ Ryusuke Ae $^{b} \quad$ Teppei Sasahara $^{c}$ \\ ${ }^{a}$ Health Service Center, Jichi Medical University, Tochigi, Japan; ${ }^{b}$ Division of Public Health, \\ Center for Community Medicine, Jichi Medical University, Tochigi, Japan; 'Division of \\ Clinical Infectious Diseases, Department of Infection and Immunity, Jichi Medical \\ University, Tochigi, Japan
}

\section{Keywords}

Hepatic angiosarcoma · Fatty liver · Liver cirrhosis

\begin{abstract}
In the current study, we report a case of a 46-year-old man who presented with sudden abdominal pain and was diagnosed with rupture of hepatic angiosarcoma (HAS). He underwent surgery, but died 13 days after the onset of the abdominal pain. Chronic exposure to carcinogens, such as thorium dioxide, arsenic, vinyl chloride, and radium, is associated with HAS. However, our patient had not been exposed to such carcinogens. He had submitted himself for annual medical checkups since he was employed. His liver was cirrhotic, and medical history data showed that he had had fatty liver for at least 10 years before HAS onset. Although liver cirrhosis may play a role in the occurrence of HAS, the connection of chronic fatty liver in the tumorigenesis remains unclear. Case reports regarding HAS with fatty liver are few. To the best of our knowledge, this is the first case of HAS occurring in a cirrhotic liver that advanced from persistent fatty stage. Given that HAS is a rare tumor, data collection is important for investigating its pathophysiology. Case presentations considering health conditions before HAS onset are limited; therefore, we present a case of HAS with annual health checkup data before disease onset.




\section{Case Reports in Oncology}

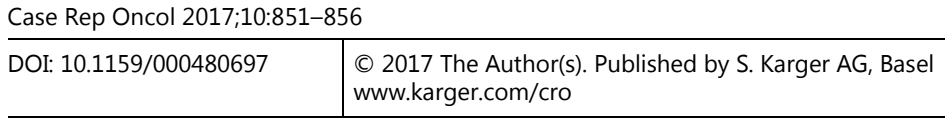

Ogawa et al.: Primary Hepatic Angiosarcoma: A Case Report with 10-Year Patient Medical Data

\section{Introduction}

Hepatic angiosarcoma (HAS) is a rare type of liver cancer and is often fatal [1]. Chronic exposure to chemicals, such as thorium dioxide, arsenic, vinyl chloride, and radium, has been associated with HAS [2]. However, the etiology of HAS remains unknown [3].

Several reports have focused on the diagnosis, imaging findings, characteristics, treatment, and clinical outcomes of HAS [4-9]. However, reports regarding the health condition of patients before disease development are limited. Collecting cases is important to further understand HAS, and data on the health condition before HAS onset may be useful. In Japan, an annual medical checkup is mandatory for employees; therefore, their health condition can be evaluated annually.

One of the authors is an occupational physician in a factory near the patient's workplace and encountered a case of primary HAS.

In this paper, we present a primary case of HAS that was detected in the cirrhotic liver, which was a consequence of persistent fatty liver for at least 10 years. Fatty liver was detected through the annual medical checkup. Previous reports have focused on disease etiology; however, in this paper, we discuss the case with consideration of the annual medical checkup data before disease onset.

\section{Case Presentation}

A 46-year-old male worker suddenly complained of right lateral abdominal pain during work, thus prompting a visit to the company clinic.

He claimed the pain was colic. Upon examination, tenderness was noted in the right hypochondrium, and the patient complained of a knock pain at the lower part of the right ribs. Costovertebral angle knock pain was unclear. He was alert, his eyes were not icteric, and the conjunctiva was not pale. His body temperature was $36.7^{\circ} \mathrm{C}$, and vital signs were normal. Urine occult blood was absent. Before the pain onset, he had not performed any strenuous tasks, and no blunt trauma was reported.

Considering the nature of the pain, the patient's age, and location of tenderness, we suspected that the abdominal pain was due to a gallstone. However, ultrasound examination was not available in the clinic; therefore, he was transferred to another medical clinic for an immediate ultrasound examination. Subsequent ultrasound examination revealed no stones in the gall bladder. However, a liver tumor was detected on the right lobe. Consequently, he was transferred on the same day to hospital A.

A computed tomography (CT) scan was urgently performed at hospital A, where liver cirrhosis and atypical liver tumor were detected. The patient's vital signs remained stable, and he was given an analgesic for his abdominal pain. He was scheduled for further tests and instructed to rest at home before the next examinations.

Three days later, he complained of severe abdominal pain and saw a doctor urgently at hospital A. CT showed bleeding from the liver tumor. Therefore, he was transferred to another hospital (hospital B) by ambulance for further management. 


\section{Case Reports in Oncology}

In hospital B, emergency transarterial embolization and hepatorrhaphy was performed, and pathological examination showed that the liver tumor was HAS. His liver function worsened because of massive bleeding, and he died 13 days after the onset of abdominal pain.

In Japan, an annual medical checkup is mandatory for workers. Hb, Ht, AST, ALT, $\gamma$-GTP, cholesterol, and triglyceride levels are checked for those aged 35 years and over. Data of the patient's annual medical checkup since he was employed are shown in Table 1 . When the patient was 35 years old, although his AST and ALT levels were within normal limits, the $\gamma$ GTP level was slightly elevated. He consumed approximately $350 \mathrm{~mL}$ of beer every day at that time. Therefore, the elevation was suspected to be due to alcohol consumption. He worked outside Japan for 1 year between the age of 36 and 37; hence no medical data were available when he was 36 years old. After returning to Japan at the age of 37, he underwent a medical checkup. His ALT, AST, and $\gamma$-GTP levels were 36, 45, and $141 \mathrm{IU} / \mathrm{L}$, respectively. He was instructed to undergo a complete medical examination. Ultrasound results revealed a fatty liver. After restriction of alcohol intake, his $\gamma$-GTP levels decreased to $85 \mathrm{IU} / \mathrm{L}$. Hepatitis due to virus or autoimmune diseases were ruled out. He was not obese and did not have thyroid disease, diabetes mellitus, or hyperlipidemia. Therefore, the elevated serum markers and fatty liver were suspected to be due to alcohol consumption. Since then, he became a social drinker. However, despite his restricted alcohol intake, laboratory tests showed continuous elevation of ALT and $\gamma$-GTP levels. At the ages of 38 and 39, he underwent an ultrasound examination again because of high $\gamma$-GTP, and the finding still showed a fatty liver. Since the age of 40 , he had not undergone any ultrasound examination. However, the diagnosis of fatty liver was considered based on the laboratory data.

Consequently, his HAS was detected in the cirrhotic liver, which was a consequence of persistent fatty liver for at least 10 years. According to his employer, although the patient worked for a manufacturing company, he did not handle any carcinogenic substances that could cause HAS.

\section{Discussion}

Although HAS is associated with exposure to chemical carcinogens [2], the cause of HAS in the majority of the cases is unknown [3]. In the current case, the patient had not handled arsenic, vinyl chloride monomer, thorium dioxide, or radium, but the disease was believed to be primary HAS.

Several studies reported the comorbidity of HAS and liver cirrhosis $[5,7,8]$, and our patient also had liver cirrhosis. However, several reports regarding the association of HAS with liver cirrhosis had conflicting findings. Locker et al. [2] reported that the association of HAS with cirrhosis, whether playing a direct causative role or not, had been underrecognized. Zocchetti [10] reported that the etiology of HAS is largely unknown. Meanwhile, Soini et al. [11] reported that HAS was positively associated with liver cirrhosis. A total of $60-97 \%$ of hepatocellular carcinoma (HCC) cases occur with liver cirrhosis, although HCC can also occur alone $[12,13]$. Locker et al. [2] reported that $40 \%$ of hepatic fibrosis or cirrhosis was noted during the autopsy of HAS patients. Xiao and Li [5] reported 2 cases (33.3\%) of liver cirrhosis among 6 HAS cases, while Pickhardt et al. [7] reported 15 cases (42.9\%) of liver cirrhosis among 35 HAS cases. Although the incidence of liver cirrhosis and HAS is significantly lower 


\section{Case Reports in Oncology}

Ogawa et al.: Primary Hepatic Angiosarcoma: A Case Report with 10-Year Patient Medical Data

than that of liver cirrhosis and HCC, liver cirrhosis may play a role in the development of HAS. However, the association is inadequate to explain epidemiologically.

Our patient had fatty liver for a relatively long time (at least 10 years). Unfortunately, only few studies have reported on the association of HAS with fatty liver. Millan et al. [14] reported a case of HAS with a 7-year history of fatty liver. HAS with nonalcoholic steatohepatitis was also reported in Japan (unpubl. data). However, fatty liver has not been reported in the HAS cases with liver cirrhosis [2, 4-9]. Therefore, although fatty liver can advance to liver cirrhosis regardless of an alcoholic etiology [15], and despite the limited evidence regarding the correlation between fatty liver and HAS, the comorbidity of fatty liver and HAS was postulated to be lower than that of liver cirrhosis and HAS.

In previous studies, HAS was not detected in the cirrhotic liver, which was a consequence of persistent fatty liver. Therefore, this is the first report on HAS occurring in the cirrhotic liver that advanced from persistent fatty liver. In our case, the previous laboratory data before disease onset, even if limited, were available because the patient had been working for the same company. No previous studies have included the patient's health history before disease onset, which increases the validity and importance of our current report.

This report has some limitations. First, patient details after he was taken to hospital A were subjective based on the patient's family and records from the previous medical clinic. Therefore, descriptions concerning the examination or treatment at hospitals A and B are insufficient. Second, the laboratory data before disease onset were based on the tests mandated by Japanese regulations. The assessment data were limited because the health checkup was only performed to evaluate general health condition, and no disease-specific tests, such as tumor marker evaluation, were performed. Given that HAS is a rare tumor and that its etiology remains unclear $[3,10]$, collecting data regarding HAS cases is important to further understand the disease. As such, we report a case of HAS and present 10-year medical data from the patient's annual checkup before disease onset.

\section{Statement of Ethics}

The authors have no ethical conflicts to disclose.

\section{Disclosure Statement}

The authors declare no conflicts of interest.

\section{References}

\footnotetext{
1 Huang NC, Wann SR, Chang HT, Lin SL, Wang JS, Guo HR: Arsenic, vinyl chloride, viral hepatitis, and hepatic angiosarcoma: a hospital-based study and review of literature in Taiwan. BMC Gastroenterol 2011;11:142.

-2 Locker GY, Doroshow JH, Zwelling LA, Chabner BA: The clinical features of hepatic angiosarcoma: a report of four cases and a review of the English literature. Medicine (Baltimore) 1979;58:48-64.
} 


\section{Case Reports in Oncology}

\begin{tabular}{l|l}
\hline Case Rep Oncol 2017;10:851-856 \\
\hline DOI: $10.1159 / 000480697$ & $\begin{array}{l}\text { C } 2017 \text { The Author(s). Published by S. Karger AG, Basel } \\
\text { www.karger.com/cro }\end{array}$ \\
\hline
\end{tabular}

Ogawa et al.: Primary Hepatic Angiosarcoma: A Case Report with 10-Year Patient Medical Data

3 Falk H, Thomas LB, Popper H, Ishak KG: Hepatic angiosarcoma associated with androgenic-anabolic steroids. Lance 1979;2:1120-1123.

4 Chen G, Li J, Wan R, Wang G, Shi J: Primary hepatic angiosarcoma in a 64-year-old man: a case report. Oncol Lett 2016;11:2445-2448.

5 Xiao FD, Li Q: Primary hepatic angiosarcoma: a retrospective analysis of 6 cases. J Dig Dis 2012;13:381385.

-6 Lin YH, Lin CC, Concejero AM, Yong CC, Kuo FY, Wang CC: Surgical experience of adult primary hepatic sarcomas. World J Surg Oncol 2015;13:87.

7 Pickhardt PJ, Kitchin D, Lubner MG, Ganeshan DM, Bhalla S, Covey AM: Primary hepatic angiosarcoma: multi-institutional comprehensive cancer centre review of multiphasic CT and MR imaging in 35 patients. Eur Radiol 2015;25:315-322. Tran Minh M, Mazzola A, Perdigao F, Charlotte F, Rousseau G, Conti F: Primary hepatic angiosarcoma and liver transplantation: radiological, surgical, histological findings and clinical outcome. Clin Res Hepatol Gastroenterol 2017, DOI: 10.1016/j.clinre.2017.02.006. Zhu YP, Chen YM, Matro E, Chen RB, Jiang ZN, Mou YP, Hu HJ, Huang CJ, Wang GY: Primary hepatic angiosarcoma: a report of two cases and literature review. World J Gastroenterol 2015;21:6088-6096. Zocchetti C: Liver angiosarcoma in humans: epidemiologic considerations (in Italian). Med Lav 2001;92:39-53.

11 Soini Y, Welsh JA, Ishak KG, Bennett WP: p53 mutations in primary hepatic angiosarcomas not associated with vinyl chloride exposure. Carcinogenesis 1995;16:2879-2881.

-12 Kumar R, Saraswat MK, Sharma BC, Sakhuja P, Sarin SK: Characteristics of hepatocellular carcinoma in India: a retrospective analysis of 191 cases. QJM 2008;101:479-485.

13 Paul SB, Chalamalasetty SB, Vishnubhatla S, Madan K, Gamanagatti SR, Batra Y, Gupta SD, Panda SK, Acharya SK: Clinical profile, etiology and therapeutic outcome in 324 hepatocellular carcinoma patients at a tertiary care center in India. Oncology 2009;77:162-171.

14 Millan M, Delgado A, Caicedo LA, et al: Liver angiosarcoma: Rare tumour associated with a poor prognosis, literature review and case report. Int J Surg Case Rep 2016;28:165-168.

-15 Liu J: Ethanol and liver: recent insights into the mechanisms of ethanol-induced fatty liver. World J Gastroenterol 2014;20:14672-14685. 


\section{Case Reports in Oncology}

\begin{tabular}{l|l}
\hline Case Rep Oncol 2017;10:851-856 \\
\hline DOI: $10.1159 / 000480697$ & $\begin{array}{l}\text { C } 2017 \text { The Author(s). Published by S. Karger AG, Basel } \\
\text { www.karger.com/cro }\end{array}$ \\
\hline
\end{tabular}

Ogawa et al.: Primary Hepatic Angiosarcoma: A Case Report with 10-Year Patient Medical Data

Table 1. The 10-year data from the patient's annual health checkup before disease onset

\begin{tabular}{|c|c|c|c|c|c|c|c|c|c|c|c|c|c|c|}
\hline $\begin{array}{l}\text { Age, } \\
\text { years }\end{array}$ & $\begin{array}{l}\text { Height, } \\
\mathrm{cm}\end{array}$ & $\begin{array}{l}\text { Weight, } \\
\text { kg }\end{array}$ & BMI & $\begin{array}{l}\text { Blood } \\
\text { pressure, } \\
\text { mm Hg }\end{array}$ & $\begin{array}{l}\mathrm{Hb}, \\
\mathrm{g} / \mathrm{dL}\end{array}$ & $\begin{array}{l}\text { Plt, } \\
\times 10^{4} \mu \mathrm{L}\end{array}$ & $\begin{array}{l}\text { LDL- } \\
\text { Chol, } \\
\mathrm{mg} / \mathrm{dL}\end{array}$ & $\begin{array}{l}\mathrm{TG}, \\
\mathrm{mg} / \mathrm{dL}\end{array}$ & $\begin{array}{l}\text { AST, } \\
\text { IU/L }\end{array}$ & $\begin{array}{l}\text { ALT, } \\
\text { IU/L }\end{array}$ & $\begin{array}{l}\gamma \text {-GTP, } \\
\text { IU/L }\end{array}$ & $\begin{array}{c}\text { Urinalysis } \\
\text { (Prot.Glu.) }\end{array}$ & $\begin{array}{l}\text { Ultraso- } \\
\text { nography } \\
\text { exam }\end{array}$ & Alcohol intake \\
\hline 24 & 179.5 & 70.5 & 21.9 & $126 / 66$ & & & & & & & & $-/-$ & & \multirow{14}{*}{$\begin{array}{l}\text { Beer } \\
350 \mathrm{~mL} / \text { day, } \\
\text { every day }\end{array}$} \\
\hline 25 & 178 & 68 & 21.5 & $118 / 60$ & 13.8 & & $178^{a}$ & 115 & 21 & 17 & 44 & $-/-$ & & \\
\hline 26 & 178 & 68.5 & 21.6 & $122 / 70$ & & & & & & & & $-/-$ & & \\
\hline 27 & 178 & 70 & 22.1 & $128 / 58$ & & & & & & & & $-/-$ & & \\
\hline 28 & 178 & 73 & 23.0 & $116 / 64$ & & & & & & & & $-/-$ & & \\
\hline 29 & 178 & 72 & 22.7 & $122 / 60$ & & & & & & & & $-/-$ & & \\
\hline 30 & 178 & 72 & 22.7 & $120 / 66$ & & & & & & & & $-/-$ & & \\
\hline 31 & 178 & 74 & 23.4 & $124 / 62$ & & & & & & & & $-/-$ & & \\
\hline 32 & 178 & 74 & 23.4 & $132 / 72$ & & & & & & & & $-/-$ & & \\
\hline 33 & 178 & 74 & 23.4 & $114 / 60$ & & & & & & & & $-/-$ & & \\
\hline 34 & 178 & 74.5 & 23.5 & $119 / 67$ & & & & & & & & $-/-$ & & \\
\hline 35 & 178 & 74.5 & 23.5 & $114 / 72$ & 13.5 & & 163 & 88 & 25 & 23 & 78 & $-/-$ & & \\
\hline 36 & & & & & & & & & & & & & & \\
\hline 37 & 178.8 & 79.3 & 24.8 & $112 / 74$ & 14.4 & & 121 & 132 & 36 & 45 & 141 & $-/-$ & Fatty liver & \\
\hline 38 & 178.6 & 73.6 & 23.1 & $106 / 64$ & 13.9 & & 93 & 115 & 28 & 26 & 104 & $\pm /-$ & Fatty liver & \multirow[t]{8}{*}{ Social drinker } \\
\hline 39 & 179.1 & 74.8 & 23.3 & $132 / 76$ & 14.3 & 14.8 & 144 & 94 & 34 & 33 & 117 & $-/-$ & Fatty liver & \\
\hline 40 & 178.5 & 77.4 & 24.3 & $105 / 63$ & 14 & & 110 & 120 & 32 & 39 & 87 & $-/-$ & & \\
\hline 41 & 179.1 & 76.5 & 23.8 & $115 / 69$ & 13.7 & & 124 & 80 & 44 & 38 & 66 & $-/-$ & & \\
\hline 42 & 178.5 & 75 & 23.5 & $116 / 70$ & 14.4 & & 124 & 113 & 26 & 31 & 78 & $-/-$ & & \\
\hline 43 & 178.3 & 74.5 & 23.4 & $129 / 83$ & 14.2 & & 110 & 121 & 27 & 38 & 52 & $-/-$ & & \\
\hline 44 & 178.4 & 78.4 & 24.6 & $108 / 70$ & 14.4 & & 108 & 172 & 39 & 51 & 81 & $-/-$ & & \\
\hline 45 & 178.3 & 83 & 26.1 & $120 / 69$ & 15 & & 138 & 115 & 42 & 65 & 96 & $-/-$ & & \\
\hline
\end{tabular}

Italicized values are above reference levels. Plt, platelets; TG, triglycerides. Blank column, no data available. a Total cholesterol. 